\title{
Pemahaman Soteriologi Alkitabiah Mahasiswa Kristen UNS Surakarta
}

\author{
Christian Students' Biblical Understanding of Soteriology \\ at UNS Surakarta
}

\author{
Timotius Haryono \\ Sekolah Tinggi Teologi Gamaliel \\ tharyono58@gmail.com
}

Kezia Yemima

Sekolah Tinggi Teologi Gamaliel

keziayemimas3@gmail.com

\begin{tabular}{|c|c|}
\hline Article Info & Abstract \\
\hline $\begin{array}{l}\text { Submitted: } \\
\text { May } 14,2020 \\
\text { Review Start: } \\
\text { May } 17,2020 \\
\text { Accepted: } \\
\text { Sept } 2,2020\end{array}$ & $\begin{array}{l}\text { Christian students haven't fully understand biblical soteriology, This contidion } \\
\text { is made worse by the effect of Christian Religious Education course to christian } \\
\text { students' understanding on biblical soteriology that remain unknown. This } \\
\text { research aims to understand the effect of Christian Religious Education course } \\
\text { to christian students' understanding on biblical soteriology. The research uses } \\
\text { quantitative approach with one group pretest postest method. Population in } \\
\text { this research is } 41 \text { Christian Bachelor's program students of } 2019 \text { taking }\end{array}$ \\
\hline $\begin{array}{l}\text { Keywords: } \\
\text { soteriology, } \\
\text { christian religious, } \\
\text { quantitative, } \\
\text { christian education } \\
\text { education research. }\end{array}$ & $\begin{array}{l}\text { Christian Religious Education course at Faculty of Engineering of Sebelas } \\
\text { Maret University (UNS). Research findings: (1) Christian Religious Education } \\
\text { course give 13.5\% understanding of christian students on biblical soteriology; } \\
\text { (2) Christian Religious Education course affected by teaching intensity, variety } \\
\text { of teaching methods, and course material. } \\
\text { [Mahasiswa Kristen belum mengerti secara penuh soteriologi alkitabiah. } \\
\text { Kondisi buruk ini diperparah dengan belum diketahuinya sumbangan } \\
\text { pengajaran mata kuliah PAK terhadap pemahaman mahasiswa Kristen di } \\
\text { perguruan tinggi tentang soteriologi alkitabiah. Penelitian ini memiliki tujuan } \\
\text { mengetahui sumbangan pembelajaran mata kuliah PAK terhadap pemahaman } \\
\text { mahasiswa Kristen, tentang soteriologi alkitabiah. Penelitian ini menggunakan } \\
\text { pendekatan kuantitatif dan metode one group pretest postest. Populasi } \\
\text { penelitian ini adalah } 41 \text { mahasiswa Kristen angkatan } 2019 \text { yang mengambil } \\
\text { Mata Kuliah Pendidikan Agama Kristen di Fakultas Teknik, Universitas } \\
\text { Sebelas Maret (UNS) program Sarjana (S1). Temuan penelitian: (1) Pengajaran } \\
\text { mata kuliah PAK menyumbangkan 13,5\% pemahaman mahasiswa Kristen } \\
\text { tentang soteriokogi alkitabiah; (2) Pengajaran mata kuliah PAK sangat } \\
\text { diperngaruhi intensitas dan variasi metode penyampaian serta materi yang } \\
\text { disampaikan.] }\end{array}$ \\
\hline
\end{tabular}




\section{PENDAHULUAN}

$\mathrm{P}$ erguruan tinggi umum (maksud peneliti perguruan tinggi non teologi) di Indonesia memiliki Pendidikan Agama Kristen (PAK) sebagai bagian dari kurikulum mata kuliah umum. Pendidikan Agama Kristen harus diikuti oleh mahasiswa yang beragama Kristen. Mata kuliah PAK, pada umumnya di perguruan tinggi umum, diajarkan satu kali dalam masa pendidikan mahasiswa di perguruan tinggi. Keputusan Direktur Jenderal Pendidikan Tinggi Departemen Pendidikan Nasional Republik Indonesia Nomor: 38/DIKTI/Kep/2002 mendefinisikan PAK sebagai suatu pembinaan yang bertujuan untuk mendasari pengertian mahasiswa ketika berproses menjadi seorang sarjana yang berkepribadian dewasa yang mementingkan nilai kemanusiaan dan kehidupan. ${ }^{1}$

Mata kuliah PAK membahas sepuluh tema dalam perkuliahan. Salah satu dari sepuluh tema tersebut adalah tentang karya Yesus yang menyelamatkan manusia (soteriologi). Tema ini tidak hanya membahas tentang pengetahuan karya Yesus saja, tetapi juga penerapannya dalam perilaku dan kerohanian mahasiswa sebagai perwujudan iman. Mahasiswa Kristen sudah mengetahui karya Yesus sebelum masuk perguruan tinggi. Pengetahuan tersebut diperoleh mahasiswa Kristen dari berbagai sumber. Oleh karena itu, mahasiswa belum mengerti secara penuh karya keselamatan Yesus yang bersumber dari Alkitab (soteriologi alkitabiah).

Peneliti sebagai dosen mata kuliah PAK di Universitas Sebelas Maret Surakarta telah mengamati pandangan mahasiswa Kristen tentang mata kuliah PAK. Hasil pengamatan peneliti adalah mahasiswa merasa jenuh dengan mata kuliah PAK. Mahasiswa Kristen telah menerima pelajaran agama Kristen sejak di tingkat sekolah dasar. Karena itu, ketika mahasiswa memperoleh mata kuliah PAK di perguruan tinggi, perkuliahan tidak dianggap penting dan hanya formalitas tanpa ada minat memperlajari PAK lebih mendalam.

Kebosanan mahasiswa akan bertambah apabila tenaga pendidik (dalam hal ini dosen mata kuliah PAK) mengajarkan PAK tanpa kualitas. Maksud peneliti dengan kata tanpa kualitas adalah dosen mata kuliah PAK mengajar tanpa persiapan, penguasaan materi, dan kreativitas dalam penyampaian. Mahasiswa zaman milenial tentu menghendaki dosen mengajar dengan variasi metode pembelajaran, penguasaan materi, dan penggunaan media pembelajaran sehingga dapat menarik minat mahasiswa.

Peneliti telah mempublikasikan jurnal penelitian berjudul "Hubungan Pendidikan Agama Kristen di Universitas Sebelas Maret Surakarta Dengan Pemahaman Soteriologi Mahasiswa” pada tahun 2003. Kesimpulan yang diperoleh dalam jurnal penelitian tersebut adalah ketika mahasiswa memahami PAK maka mahasiswa juga akan memahami soteriologi. ${ }^{2}$ Tulisan karya Hendra M. Sihombing dengan judul "Soteriologi Dalam Pendidikan Agama Kristen" memberikan kesimpulan bahwa PAK seharusnya mengutamakan pemberitaan tentang karya keselamatan Yesus. ${ }^{3}$ Berdasarkan dua karya diatas peneliti berkeinginan untuk mengembangkan penelitian tentang pemahaman mahasiswa tentang soteriologi alkitabiah khususnya di Universitas Sebelas Maret. Peneliti berharap dapat mengetahui sumbangan pemahaman yang diberikan mata

${ }^{1}$ Direktur Jenderal Pendidikan Tinggi Departemen Pendidikan Nasional Republik Indonesia, "Rambu-Rambu Pelaksanaan Mata Kuliah Pengembangan Kepribadian Di Perguruan Tinggi" (2020).

2 Timotius Haryono, "Hubungan Pendidikan Agama Kristen Di Universitas Sebelas Maret Dengan Pemahaman Soteriologi Mahasiswa," Jurnal Penelitian Sekolah Tinggi Teologi Gamaliel 1, no. 2 (2013): $8-9$.

\footnotetext{
${ }^{3}$ Hendra M. Sihombing, "Soteriologi Dalam Pendidikan Agama Kristen,” 2012.
} 
kuliah PAK terhadap pemahaman mahasiswa tentang soteriologi alkitabiah. Hasil akhir yang diharapkan dari penelitian ini adalah dosen PAK dapat mengetahui pentingnya mata kuliah PAK khususnya tema soteriologi alkitabiah.

Berdasarkan penjelasan latar belakang penelitian di atas, dapat diidentifikasi dua masalah yang muncul, yaitu: pertama, mahasiswa kurang berminat terhadap mata kuliah PAK di perguruan tinggi. Kedua, belum diketahui sumbangan pembelajaran mata kuliah PAK terhadap pemahaman soteriologi alkitabiah mahasiswa di perguruan tinggi.

Masalah dalam penelitian ini dibatasi pada sumbangan pembelajaran mata kuliah PAK terhadap pemahaman mahasiswa Kristen, semester satu, Fakultas Teknik, Universitas Sebelas Maret Surakarta tentang soteriologi alkitabiah.

Berdasarkan permasalahan di atas, maka masalah dalam penelitian ini dirumuskan menjadi: "Seberapa besar sumbangan pembelajaran mata kuliah PAK terhadap pemahaman mahasiswa Kristen, semester satu, Fakultas Teknik, Universitas Sebelas Maret Surakarta tentang soteriologi alkitabiah?"

Tujuan penelitian ini adalah untuk mengetahui sumbangan pembelajaran mata kuliah PAK terhadap pemahaman mahasiswa Kristen, semester satu, Fakultas Teknik, Universitas Sebelas Maret Surakarta tentang soteriologi alkitabiah.

\section{METODE PENELITIAN}

Penelitian ini adalah penelitian yang menggunakan pendekatan kuantitatif dan metode one group pretest postest design. ${ }^{4}$ Penelitian ini akan menguji pemahaman populasi tentang soteriologi alkitabiah melalui pretest dan posttest. Pretest akan memperlihatkan pemahaman populasi tentang soteriologi alkitabiah sebelum pengajaran mata kuliah PAK. Sedangkan, posttest akan memperlihatkan pemahaman populasi tentang soteriologi alkitabiah setelah pengajaran mata kuliah PAK. Dengan menganalisis data pretest dan posttest, maka sumbangan pengajaran PAK terhadap pemahaman populasi tentang soteriologi alkitabiah.

Populasi penelitian ini adalah mahasiswa Kristen angkatan 2019 yang mengambil mata kuliah PAK di Fakultas Teknik Universitas Sebelas Maret Surakarta (UNS) program Sarjana (S1). Populasi berjumlah 41 mahasiswa dan seluruhnya merupakan sampel dalam penelitian ini.

Penelitian ini menggunakan angket kuesioner sebagai instrumen penelitian. Angket kuesioner telah diuji cobakan kepada 25 mahasiswa Kristen angkatan 2019 Universitas Sebelas Maret dari fakultas yang berbeda untuk tujuan validasi. Validasi angket penelitian menggunakan uji validitas dan reliabilitas instrumen.

Penelitian ini menganalisis data melalui empat pengujian yaitu uji normalitas, uji homogenitas, uji hipotesis dan uji sumbangan efektivitas. Uji normalitas data pada penelitian ini menggunakan rumus kolmogorov smirnov. Data dikatakan terdistribusi normal bila nilai sigifikansi lebih besar dari atau sama dengan 0,05 , sedangkan bila nilai signifikansi lebih kecil dari 0,05 maka data tidak terdistribusi normal. Uji homogenitas dalam penelitian ini menggunakan model Levene Test for Equality of Variance. Apabila nilai signifikansi lebih besar dari atau sama dengan 0,05 maka varian data yang dinyatakan memiliki sifat yang sama atau homogen. Bila nilai signifikansi kurang dari 0,05 maka varian data yang dinyatakan memiliki sifat berbeda atau heterogen dan tidak dapat dilanjutkan pengujian berikutnya. Uji hipotesis dalam penelitian ini menggunakan paired sample T-test. Data pretest dan posttest dikatakan memiliki

\footnotetext{
${ }^{4}$ Sugiyono, Metode Penelitian Tindakan Komprehensif (Bandung: Alfabeta, 2015), 138.
} 
perbedaan yang signifikan apabila nilai signifikansinya kurang dari atau sama dengan 0,05 . Data pretest dan posttest tidak memiliki perbedaan apabila nilai signifikansinya lebih dari 0,05 . Uji sumbangan efektivitas dalam penelitian ini menggunakan uji unvariate. Uji ini bertujuan melihat sumbangan PAK terhadap pemahaman mahasiswa terhadap soteriologi alkitabiah. Sumbangan akan dilihat dari penghitungan nilai R Square dari pretest dan posttest. Apabila nilai R Square positif berarti pengajaran mata kuliah PAK menyumbang pemahaman mahasiswa tentang soteriologi alkitabiah. Apabila nilai R Square negatif berarti pengajaran mata kuliah PAK mengurangi pemahaman mahasiswa tentang soteriologi alkitabiah.

Hipotesis penelitian ini adalah PAK berpengaruh efektif terhadap pemahaman mahasiswa Kristen di perguruan tinggi tentang soteriologi alkitabiah. Hipotesis ini terbukti apabila ada signifikasi pada uji hipotesis dan ada nilai positif pada R square uji sumbangan efektifitas.

\section{HASIL DAN PEMBAHASAN}

\section{Kajian Teori}

Perguruan tinggi memberikan pendidikan agama bagi mahasiswa sesuai dengan agama yang diyakininya. Mata kuliah PAK menyediakan pendidikan Agama Kristen bagi mahasiswa yang beragama Kristen. Mata kuliah agama merupakan salah satu dari tiga mata kuliah Pengembangan Kepribadian. Mata kuliah Pengembangan Kepribadian lain adalah Pendidikan Pancasila dan Pendidikan Kewarganegaraan. ${ }^{5}$

Mata kuliah PAK memiliki tujuan membantu mahasiswa Kristen agar mampu mengalami dan merasakan kasih Allah dalam Yesus Kristus melalui pimpinan Roh Kudus sehingga dapat berkembang menjadi pribadi yang sempurna dalam segala aspek. Melalui mata kuliah PAK, mahasiswa juga didorong untuk membuktikan dirinya sebagai manusia baru yang dewasa dan siap memikul tanggung jawab untuk melakukan kebenaran bagi kepentingan Allah, sesama manusia dan alam lingkungan. Mata kuliah PAK juga hendak menghasilkan mahasiswa Kristen yang bersedia memberikan hidup dan pekerjaan demi tujuan kemanusiaan. ${ }^{6}$

Materi mata kuliah PAK akan menciptakan mahasiswa Kristen yang menjadikan agama sebagai dasar nilai dan petunjuk dalam mewujudkan kepribadian Kristen yang mengutamakan harkat dan martabat manusia. Oleh karena itu, mata kuliah PAK memperlengkapi mahasiswa agar dapat menyatakan nilai-nilai Kristen dalam arti mewujudkan kasih, keadilan dan kebenaran dalam keluarga, masyarakat dan dalam seluruh aspek kehidupan. ${ }^{7}$ Mata kuliah PAK mengajari mahasiswa Kristen dengan ajaran-ajaran kekristenan. ${ }^{8}$ Karena itu, mata kuliah PAK memiliki 10 tema kajian yaitu Tuhan Yang Maha Esa, manusia, Jemaat, moral, ilmu pengetahuan, teknologi dan seni, masyarakat, budaya, politik, hukum dan kerukunan umat beragama. ${ }^{9}$

Materi mata kuliah PAK dengan tema Tuhan Yang Maha Esa dan Manusia merupakan tema yang terdapat dalam pemahaman soteriologi alkitabiah. Tema ini perlu diajarkan dengan

5 Haryono, "Hubungan Pendidikan Agama Kristen Di Universitas Sebelas Maret Dengan Pemahaman Soteriologi Mahasiswa."

${ }^{6}$ Daniel Nuhamara, Pendidikan Agama Kristen (Bandung: Bina Media Informasi, 2005), xx.

${ }^{7}$ Mariani Harmadi and Agung Jatmiko, "Pembelajaran Efektif Pendidikan Agama Kristen Generasi Milenial," PASCA : Jurnal Teologi Dan Pendidikan Agama Kristen 16, no. 1 (2020): 62-74, https://doi.org/10.46494/psc.v16i1.72.

${ }^{8}$ Mardiharto, "Pembangunan Sumber Daya Manusia Melalui Bidang Pendidikan Agama Kristen," PASCA: Jurnal Teologi Dan Pendidikan Agama Kristen 15, no. 2 (2019): 30-31.

9 Timotius Haryono, Pendidikan Agama Kristen (Surakarta: Lembaga Pengembangan dan Penjaminan Mutu Pendidikan (LPPMP) Universitas Sebelas Maret, 2016), 1-3. 
metode yang bervariasi. Harmadi dan Jatmiko, mengutip pendapat Sijabat, menjelaskan bahwa mata kuliah pendidikan agama Kristen perlu menggunakan empat bentuk pembelajaran agar strategi pembelajaran efektif. Empat bentuk itu adalah olah hati, rasa, karsa dan raga. ${ }^{10}$ Oleh karena itu, mata kulian PAK tidak mungkin hanya menggunakan bentuk ceramah saja untuk menyampaikan materi.

Mata kuliah PAK pada umumnya memiliki 16 kali pertemuan dengan beban dua SKS (satuan kredit semester). Mata kuliah PAK menghabiskan durasi 100 menit setiap pertemuan. Materi pembelajaran diajarkan dengan metode bervariasi dan mahasiswa menjadi pusat pembelajaran atau Student Centered Learning. Mata kuliah PAK menggunakan tugas pribadi, pemahaman Alkitab dalam kelompok, retrit, persekutuan bersama dan praktik lapangan untuk memenperdalam pemahaman mahasiswa tentang materi yang diajarkan.

Konteks pembelajaran dalam mata kuliah PAK adalah mahasiswa. Mahasiswa merupakan orang yang belajar di jenjang Perguruan Tinggi. Mahasiswa Kristen harus mengikuti mata kuliah PAK. Undang-Undang Republik Indonesia Nomor 12 Tahun 2012 tentang Pendidikan Tinggi khususnya pasal 35 ayat 3 merupakan dasar mengapa mahasiswa Kristen harus mengikuti mata kuliah PAK. ${ }^{11}$ Undang-undang ini memberikan landasan formal bagi kehadiran mata kuliah PAK di perguruan tinggi. ${ }^{12}$ Mahasiswa bertanggung jawab untuk melaksanakan pembelajaran setiap mata kuliah yang diambil. Karena itu, mahasiswa dituntut untuk dapat memahami, menganalisis, mengkomunikasikan, mensintesiskan, dan menerapkan ilmu yang diperoleh pada setiap mata kuliah.

Titik awal mahasiswa dapat menerapkan ilmu PAK adalah dengan memahami soteriologi alkitabiah. Soteriologi alkitabiah yang dimaksudkan dalam penelitian ini adalah karya Yesus bagi keselamatan manusia secara pribadi yang tercantum dalam Alkitab. Karya Yesus bagi keselamatan manusia adalah usaha penyelamatan manusia yang dilakukan oleh Yesus menurut Alkitab. Efi menegaskan bahwa keselamatan yang dimaksud Alkitab adalah masuk kerajaan Allah. Orang yang diselamatkan menjadi anak-anak Allah (Yoh 1:12), menjadi milik Kristus (Roma 8:9; 1 Kor. 6:10), memperoleh hidup kekal (Yoh 3:16), mendapat pengampunan dosa (Ef. 1:7), dibebaskan dari kuasa dosa (Rom 6:18), dibebaskan dari kutukan (Gal 3:13) dan dibebaskan dari kuasa Iblis (Kol 1:13). ${ }^{13}$ Oleh karena itu soteriologi alkitabiah terkait dengan dua substansi dalam PAK yaitu Tuhan Yang Maha Esa dan Manusia.

Soteriologi alkitabiah, tentang karya Yesus Kristus bagi keselamatan manusia, menempati ajaran yang penting dalam kekristenan. Pentingnya karya Yesus ini terlihat dalam pengakuan iman rasuli dimana sebagian besar berisi fakta tentang karya Yesus Kristus. Nama Kristen juga berasal dari orang-orang yang mengikut Kristus. ${ }^{14}$ Orang Kristen sudah seharusnya mempelajari dan mengerti soteriologi alkitabiah. Dasar karya Yesus Kristus bagi keselamatan manusia adalah Alkitab. Karya ini merupakan salah satu dari dogmatika Kristen. Di dalam usaha

\footnotetext{
${ }^{10}$ Harmadi and Jatmiko, "Pembelajaran Efektif Pendidikan Agama Kristen Generasi Milenial."

11 Presiden Republik Indonesia, "Undang-Undang Republik Indonesia Nomor 12 Tahun 2012 Tentang Pendidikan Tinggi”" (2012).

12 Paristiyanti Nurwardani, Pedidikan Agama Kristen (Direktorat Jenderal Pembelajaran dan Kemahasiswaan Kementerian Riset, Teknologi, dan Pendidikan Tinggi Republik Indonesia, 2016), 24.

${ }^{13}$ Efi Nurwindayani, "Doktrin Keselamatan Untuk Orang Kristen Jawa,” Jurnal Penelitian Sekolah Tinggi Teologi Gamaliel 5, no. 2 (2017): 36-50.

${ }^{14}$ Nurwardani, Pedidikan Agama Kristen.
} 
dogmatika, manusia mau menyelidiki kebenaran dari Allah yaitu Alkitab. ${ }^{15}$ Orang Kristen dan mahasiswa Kristen yang mamahami soterilogi alkitabiah akan mengalami perubahan hidupnya baik dari worldviewnya maupun kepribadiannya.

Komponen Soteriologi alkitabiah adalah pertama, jati diri manusia. Manusia merupakan ciptaan Allah yang diciptakan segambar dan serupa Allah. ${ }^{16}$ Dimensi manusia sebagai ciptaan yang serupa dan segambar Allah yaitu, pertama, manusia adalah makhluk jasmani (tubuh jasmani) dan spiritual atau rohani (Yunani: Zoe, memiliki hidup rohani) yang hidup kekal (seperti Allah yang kekal). Manusia adalah makhluk rasional yang memiliki daya cipta serupa Allah yang adalah sang Pencipta. Manusia adalah makhluk bermoral yang sanggup memutuskan perihal etis (Kej 2:16-17). Manusia adalah makhluk sosial yang membutuhkan manusia lain (Kej 2:18-20). ${ }^{17}$

Status segambar dan serupa Allah ini dirusak manusia karena ia berdosa. Dalam Kejadian 3, keberdosaan terjadi akibat Adam dan Hawa secara sengaja memakan buah pengetahuan baik dan jahat. Perbuatan ini adalah pelanggaran terhadap perintah Tuhan yang melarang manusia untuk memakannya. Oleh karena itu, manusia memenuhi salah satu definisi dosa dalam Alkitab yaitu pelanggaran atau melewati batas yang sudah ditetapkan. ${ }^{18}$

Manusia mengalami perubahan ketika melanggar perintah Tuhan. Dengan melanggar perintah Tuhan, perubahan pertama yang dialami manusia adalah menanggung hukuman yang mengubah, sebagai makhluk rohani menjadi manusia takut bertemu Allah (Kej 3:8,10, 22-24). Ketakutan bertemu Allah menandakan manusia kehilangan hidup zoe karena terpisah dari Allah. Keterpisahan ini membuat manusia tidak lagi kekal (manusia mati kekal masa kini dan akan datang).

Perubahan kedua, sebagai makhluk rasional, manusia mulai berpikir negatif terhadap semua (Kej 3:8-10). Perubahan ketiga, sebagai makhluk etis, manusia menjadi memiliki lebih banyak pilihan yang salah. Perubahan keempat, manusia menjadi memiliki emosi negatif dan perasaan bersalah (Kej 3:7,10). Perubahan kelima, sebagai makhluk sosial manusia saling menyalahkan dan timbul perpecahan (ayat Kej 3:12-14, 4: 1-8; Kej 6-11). ${ }^{19}$

Perubahan karena keberdosaan, membuat manusia membutuhkan keselamatan karena manusia ingin kembali status asali. ${ }^{20}$ Karena itu, keselamatan dalam agama Kristen tidak hanya tentang masuk surga atau neraka saja. Keselamatan dalam Kristen memiliki cakupan memiliki Roh Kristus (Rom 8:9), memiliki relasi dengan Allah (Kol 1:21-22), menjadi anak-anak Allah (Yoh 1:12) yang mewarisi Kerajaan Allah (1 Pet 2:9-10; Mar 10:23-27, memiliki hidup kekal (Rom 6:23; 1 Yoh 5:13).

Kedua, Allah dalam Yesus Kristus. Manusia tidak dapat mengenal Allah. Penyebabnya adalah manusia merupakan mahkluk yang terbatas sedangkan Allah tak terbatas. Manusia hanya bisa mengenal Allah ketika Allah menyatakan diri-Nya kepadanya. ${ }^{21}$

${ }^{15}$ G.C. van Niftrik and B.J. Boland, Dogmatika Masa Kini (Jakarta: BPK Gunung Mulia, 2015), $19-21$.

16 Haryono, "Hubungan Pendidikan Agama Kristen Di Universitas Sebelas Maret Dengan Pemahaman Soteriologi Mahasiswa."

17 Timotius Haryono, "Saved By Faith” (Sura: Yayasan Gamaliel, 2018), 7-8.

${ }^{18}$ Stephen Tong, Dosa, Keadilan Dan Penghakiman (Jakarta: Lembaga Reformed Injili Indonesia, 1993), 47.

${ }^{19}$ Stanley Heath, Penginjilan Dan Pelayanan Pribadi (Surabaya: Yakin, 1979), 58.

${ }^{20}$ Neil T. Anderson and Rich Miller, Freedom From Fear (Batam: Interaksara, 2002), 27.

${ }^{21}$ Nurwardani, Pedidikan Agama Kristen. 
Allah yang penuh kasih mengambil inisiatif untuk menyelamatkan manusia. Allah mengutus Firman-Nya menjelma menjadi manusia dalam diri Yesus Kristus. Yesus adalah Firman Allah yang menjadi manusia yang melakukan kehendak Allah yaitu karya penebusan (mati di salib, bangkit pada hari ketiga, dan naik ke Surga) dan menjadi Juruselamat (Kristus, mesias) manusia. ${ }^{22}$

Yesus adalah jalan, kebenaran dan hidup. Dalam Yohanes 14:6, Yesus secara jelas mengatakan demikian. Perkataan ini berarti bahwa Yesus adalah satu-satunya Juruselamat (Kristus) yang disaksikan oleh Alkitab. Kesaksian ini dibuktikan dengan identitas Yesus yang adalah Allah sendiri karena Ia adalah jelmaan Firman Allah (Yoh 1:14). Selain itu, Yesus memberikan kepastian bagi orang Kristen yang percaya kepada-Nya melalui karya penebusan (mati, bangkit dan naik ke Surga). Berikutnya, Yesus memberi jaminan pengampunan dosa dengan darahnya sendiri (1 Pet 1: 18-19). Yesus juga merupakan penggenapan Kristus (mesias) di Perjanjian Lama. Bukti terakhir adalah Yesus tidak berdosa dan mengajarkan etika yang tertinggi dan terlengkap yang dapat diteladani. ${ }^{23}$

Ketiga, kasih karunia Kristus. Yesus sang Kristus menyelamatkan manusia berdosa dengan menggantikan hukuman manusia. Hukuman ini diterima oleh Yesus di kayu salib. Karya ini membuat manusia ditebus dan diselamatkan. Meskipun karya ini didasari oleh kasih karunia Kristus, tetapi tidak semua orang dapat menikmatinya. Tidak semua orang berdosa menerima kasih karunia Kristus. Hanya orang yang menerima Yesus yang memperoleh kasih karunia Kristus.

Iman adalah kunci untuk menerima kasih karunia Kristus (Ef 2:8-9). Iman yang sejati memiliki urutan percaya kepada Yesus Kristus (sebagai Tuhan dan Juru Selamat secara pribadi) kemudian menerima hidup yang kekal, menjadi anak-anak Allah, dan terakhir berbuat baik dalam kehidupan setiap saat. Urutan ini menjadi ciri-ciri orang beriman yaitu mengerti akan Allah yang benar di dalam Yesus Kristus dan kebenaran Firman-Nya. Ciri lain adalah mempercayai segala yang sudah dimengerti tentang Allah, Yesus Kristus dan kebenaran Firman-Nya. Ciri berikutnya adalah menerima Yesus sebagai Tuhan dan juru selamat secara pribadi sehingga hidupnya dikuasai oleh Yesus dan memiliki anak-anak Allah. Ciri terakhir adalah menaati Firman Allah. ${ }^{24}$

Keempat, menjadi orang Kristen sejati. Orang Kristen sejati adalah orang yang didiami Roh Kristus. ${ }^{25}$ Dengan didiami oleh Roh Kristus, hidup rohani atau zoe manusia menjadi hidup kembali. Bila manusia kembali memiliki hidup rohani maka manusia bisa kembali berelasi dengan Allah yang adalah sumber hidup kekal.

Orang yang memiliki Roh Kristus memiliki ciri hatinya taat kepada Allah dan berkomitmen hidup untuk Kristus. ${ }^{26}$ Wujud nyata hati yang taat adalah mempelajari dan melakukan firman Tuhan dalam Alkitab. Wujud ketaatan lain adalah kesediaan untuk melayani jemaat atau sesama orang percaya.

Manusia berdosa dapat menerima karya keselamatan dari Yesus dengan cara memutuskan untuk bertobat dan beriman kepada Injil Yesus Kristus. Bertobat memiliki dua arti

${ }^{22}$ Haryono, "Hubungan Pendidikan Agama Kristen Di Universitas Sebelas Maret Dengan Pemahaman Soteriologi Mahasiswa."

${ }^{23}$ D.A Carson and Donald Guthrie, Tafsiran Alkitab Abad Ke-21 (Jakarta: Yayasan Komunikasi Bina Kasih/OMF, 2017), 203-5.

${ }^{24}$ Haryono, "Saved By Faith."

${ }^{25}$ W. Stanley Heath, Tak Mengambang Tak Meleset (Yogyakarta: Yayasan Andi, 1989), 38.

${ }^{26}$ Haryono, "Saved By Faith." 
pertama menyesal dan membuat keputusan untuk tidak berbuat lagi. Arti kedua dari bertobat adalah berganti haluan dan berpegang pada dasar yang benar yaitu percaya kepada Injil Yesus Kristus. $^{27}$

Langkah praktis dalam menerima karya Yesus bagi keselamatan manusia adalah pertama, menyadari bahwa dirinya seorang berdosa yang dimurkai Allah dan dihukum maut (Rom 2:23, 6:23). Kedua, menyadari dengan sungguh-sungguh bahwa usaha sendiri untuk memperoleh hidup kekal adalah sia-sia (Efesus 2:8-9). Ketiga, menyadari dengan sungguh-sungguh bahwa keselamatan (kekerajaan Allah dan hidup kekal) dapat dinikmati hanya karena kasih karunia Yesus. kemudian memercayai bahwa Yesuslah Kristus, satu-satunya jalan keselamatan karena ia sendiri telah memikul dosa-dosa kita di dalam tubuh-Nya di kayu salib. Keempat, menerima dengan sungguh-sungguh Yesus sebagai Tuhan dan Juruselamat pribadinya. Menerima Tuhan Yesus dilakukan dengan cara berdoa secara pribadi dengan mengatakan "masuklah dalam hatiku, ampnilah dosa-dosaku, tinggallah dalam hatiku dan peliharalah aku senantiasa. Terima kasih Tuhan Yesus, amin.". ${ }^{28}$

Neil T. Anderson mengatakan bahwa semua orang dalam kegelapan. Kegelapan yang dimaksudkan menunjuk kepada ketidakmampuan manusia untuk meneladani Kristus karena masalah dosa. Manusia perlu berubah kodrat dari kegelapan menjadi terang untuk dapat meneladani Kristus. Perubahan kodrat ini diperoleh dengan memahami dan menerima soteriologi alkitabiah. ${ }^{29}$

Orang yang telah menerima Yesus dan karya keselamatan-Nya mengalami perubahan dalam pandangan dunia (worldview) dan kepribadiaanya. Ia telah menjadi manusia baru akan melihat dunia dari perspektif yang baru yaitu Firman Allah. Demikian pula kepribadiannya mengalami pembaharuan rohani, batiniah, kognitif, afektif, karakter, dan konatif seiring dengan proses perkembangan rohani menuju kedewasaan penuh dalam Kristus (Efesus 4:13-15).

Soteriologi Alkitabiah memiliki arti penting dalam PAK khususnya dalam perguruan tinggi umum. Pemahaman soteriologi alkitabiah memungkinkan tujuan PAK yaitu perubahan karakter dapat tercapai. Tanpa pemahaman soteriologi alkitabiah perubahan karakter tidak mungkin dapat diwujudkan. Jura mengatakan bahwa soteriologi alkitabiah harus menjadi pusat PAK. ${ }^{30}$

Perubahan karakter dalam kekristenan dimulai dari pemahaman dan penerimaan keselamatan. Ketika seseorang menerima keselamatan dalam Yesus, maka gambar dirinya akan dipulihkan. Gambar diri yang pulih memungkinkan mahasiswa untuk memiliki karakter seperti Yesus seperti yang diharapkan dalam PAK. ${ }^{31}$

\footnotetext{
${ }^{27}$ Heath, Tak Mengambang Tak Meleset.

${ }^{28}$ Haryono, "Hubungan Pendidikan Agama Kristen Di Universitas Sebelas Maret Dengan Pemahaman Soteriologi Mahasiswa."

${ }^{29}$ Neil T. Anderson, Siapa Anda Sesungguhnya (Bandung: Lembaga Literatur Baptis, 1997), 9394.

${ }^{30}$ Demsy Jura, "Kajian Soteriologi Dalam Teologi Universalisme, Calvinisme, Dan Arminianisme Serta Kaitannya Dengan Pembelajaran Pendidikan Agama Kristen," Shanan Jurnal Pendidikan Agama Kristen 1, no. 2 (2017): 55.

${ }^{31}$ Soleman Kawangmani and Irawan Budi Lukmono, "Efektivitas Pembelajaran Agama Kristen Melalui Mata Kuliah Pendidikan Agama Kristen Di Perguruan Tinggi Terhadap Pemahaman Mahasiswa Kristen Tentang Gambar Diri," Jurnal Gamaliel: Teologi Praktika 2, no. 1 (2020), https://doi.org/10.38052/gamaliel.v2i1.48.
} 


\section{Hasil Penelitian}

Hasil penghitungan uji normalitas menggunakan rumus kolmogorov smirnov adalah sebagai berikut

Tabel 1. One-Sample Kolmogorov-Smirnov Test

\begin{tabular}{llr}
\hline & & \multicolumn{1}{c}{$\begin{array}{c}\text { Unstandardized } \\
\text { Residual }\end{array}$} \\
\hline$N$ & & 41 \\
\hline Normal Parameters & \\
& Mean & .0000000 \\
\cline { 2 - 3 } & Std. Deviation & 2.54394480 \\
\hline Most Extreme Differences & Absolute & .090 \\
\cline { 2 - 3 } & Positive & .053 \\
\cline { 2 - 3 } & Negative & -.090 \\
\hline Kolmogorov-Smirnov $Z$ & & .575 \\
\hline Asymp. Sig. (2-tailed) & & .895 \\
\hline
\end{tabular}

a. Test distribution is Normal.

Hasil penghitungan pada Tabel 1. One-Sample Kolmogorov-Smirnov Test menunjukkan nilai signifikansi 0,895 . Nilai signifikasi ini lebih besar dari $0,05(0,895 \geq 0,05)$ sehingga dapat diketahui bahwa seluruh data memiliki nilai signifikansi. Oleh karena itu, kesimpulan dari penghitungan ini adalah seluruh data postest dan pretest terdistribusi normal. Dengan data yang terdistribusi secara normal maka data-data ini dapat mewakili kondisi dari populasi dan dapat dilakukan pengujian dengan menggunakan statisik parametrik.

Hasil penghitungan uji homogenitas dalam model Levene Test for Equality of Variance adalah sebagai berikut

Tabel 2. Test of Homogeneity of Variances

\begin{tabular}{lrrrrr}
\hline & Levene Statistic & $d f 1$ & & $d f 2$ & \multicolumn{1}{c}{ Sig. } \\
\hline Posttest & 1.883 & 1 & 39 & .178 \\
\hline Pretest & .095 & 1 & 39 & .759 \\
\hline
\end{tabular}

Hasil penghitungan pada Tabel 2. Test of Homogeneity of Variances menunjukkan nilai signifikansi data pretest sebesar 0,178 dan posttest sebesar 0,759. Nilai signifikansi kedua data lebih besar dari 0,05 sehingga dapat disimpulkan data pretest dan posttest bersifat homogen.

Hasil penghitungan uji hipotesis melalui paired sample T-test adalah sebagai berikut

Tabel 3. Paired Samples Statistics

\begin{tabular}{llrrrrr}
\hline & & & & \multicolumn{2}{c}{ Std. Error } \\
& & Mean & $N$ & Std. Deviation & Mean \\
\hline \multirow{2}{*}{ Pair 1 } & Pretest & 43.24 & 41 & 3.375 & .527 \\
\cline { 2 - 7 } & Posttest & 44.34 & 41 & 2.735 & .427 \\
\hline
\end{tabular}


Tabel 4. Paired Samples Test

\begin{tabular}{|c|c|c|c|c|c|c|c|c|}
\hline \multicolumn{9}{|c|}{ Paired Differences } \\
\hline & & $\begin{array}{l}\text { Std. } \\
\text { Devi }\end{array}$ & $\begin{array}{c}\text { Std. } \\
\text { Error }\end{array}$ & $\begin{array}{r}95 \% \\
\text { Inter } \\
\text { Dif }\end{array}$ & $\begin{array}{l}\text { fidence } \\
\text { of the } \\
\text { ence }\end{array}$ & & & \\
\hline & Mean & ation & Mean & Lower & Upper & $t$ & $D f$ & Sig. (2-tailed) \\
\hline $\begin{array}{r}\text { Pair } 1 \text { Pretest - } \\
\text { Posttest }\end{array}$ & -1.098 & $\begin{array}{r}3.47 \\
7 \\
\end{array}$ & .543 & -2.195 & .000 & -2.021 & 40 & .050 \\
\hline
\end{tabular}

Hasil penghitungan pada Tabel 3. Paired Samples Statistics menunjukkan nilai rata-rata posttest $(44,34)$ lebih besar dari nilai rata-rata pretest $(43,24)$. Hasil ini menunjukkan adanya pengaruh Pengajaran PAK terhadap pemahaman mahasiswa tentang soteriologi alkitabiah. Hal ini dibuktikan dengan nilai rata-rata posttest (ujian setelah pengajaran PAK) yang lebih tinggi.

Hasil penghitungan pada Tabel 4. Paired Samples Test menunjukkan nilai signfikansi pretestposttest 0,05 . Nilai ini lebih kecil atau sama dengan margin error yaitu 0,05 . Hal ini menunjukkan ada kenaikan yang signifikan antara pretest dan posttest. Kesimpulannya adalah pengajaran PAK signifikan menyumbang pemahaman mahasiswa tentang soteriologi alkitabiah.

Hasil perhitungan R Square dalam uji sumbangan efektivitasdalam uji unvariate adalah sebagai berikut

Tabel 5. Model Summary ${ }^{\mathrm{b}}$

\begin{tabular}{lrrrrr}
\hline Model & $R$ & $R$ Square & $\begin{array}{c}\text { Adjusted } R \\
\text { Square }\end{array}$ & $\begin{array}{c}\text { Std. Error of the } \\
\text { Estimate }\end{array}$ \\
\hline$l$ & $.367^{\mathrm{a}}$ & .135 & .113 & 2.576 \\
\hline a. Predictors: (Constant), Pretest & & & \\
b. Dependent Variable: Posttest & & & \\
\hline
\end{tabular}

Nilai R square pada tabel Tabel 5. Model Summary ${ }^{\mathrm{b}}$ menunjukkan nilai 0,135 atau 13,5\%. Nilai R Square ini merupakan peningkatan nilai pretest ke posttest sebanyak 13,5\%. Dengan kata lain, ada kenaikan nilai 13,5\% dari sebelum diajar (pretest) dan setelah diajar (posttest) karena adanya pengajaran PAK. Hal ini menunjukkan bahwa PAK menyumbang 13,5\% pemahaman mahasiswa tentang soteriologi alkitabiah.

Penghitungan dari pengujian-pengujian di atas menunjukkan bahwa hipotesis peneliti terbukti. PAK berpengaruh efektif terhadap pemahaman mahasiswa Kristen di perguruan tinggi tentang soteriologi alkitabiah. Efektifitas PAK terlihat dengan menyumbang 13,5\% pemahaman mahasiswa tentang soteriologi alkitabiah.

\section{Pembahasan}

Hipotesis peneliti terbukti karena peneliti sebagai dosen agama menyampaikan materi dengan metode pembelajaran yang bervariasi dan berulang-ulang. Hasil efektif penelitian ini sesuai dengan pendapat Sijabat dalam Harmadi dan Jatmiko yang berpendapat bahwa mata kuliah PAK perlu melibatkan empat bentuk pembelajaran agar strategi pembelajaran efektif. ${ }^{32}$

\footnotetext{
${ }^{32}$ Harmadi and Jatmiko, "Pembelajaran Efektif Pendidikan Agama Kristen Generasi Milenial."
} 
Peneliti sebagai dosen mata kuliah PAK menggunakan metode intrakulikuler seperti ceramah, presentasi, diskusi dan studi mandiri. Peneliti juga menggunakan metode ekstrakulikuler yang melibatkan Persekutuan Mahasiswa Kristen Fakultas Teknik Universitas Sebelas Maret Surakarta (PMK FT UNS) sebagai Unit Kegiatan Mahasiswa (UKM) kerohanian kampus. PMK FT UNS terlibat dalam melaksanakan kegiatan kelompok pemahaman Alkitab dengan bentuk Kelompok Tumbuh Bersama Kontekstual (KTBK/Nama pemuridan yang dikerjakan di PMK FT UNS dan PMK UNS), retrit mahasiswa Kristen, persekutuan bersama mahasiswa Kristen, dan Pembekalan Rohani Awal Tahun Akademik (Kegiatan pembelakan rohani bagi mahasiswa baru PMK UNS). Dengan variasi metode ini, mahasiswa tidak merasa bosan sehingga dapat meningkatkan serapan mahasiswa terhadap materi.

Hasil efektif ini juga diperoleh karena peneliti menyampaikan materi soteriologi alkitaibah secara berulang-ulang. Peneliti menyampaikan materi soteriologi alkitabiah di kelas setidaknya empat kali. Kegiatan ekstrakulikuler menyampaikan soteriologi alkitabiah setidaknya selama empat kali pertemuan. Oleh karena itu, mahasiswa Kristen dalam penelitian ini memperoleh minimal delapan kali pembelajaran soteriologi alkitabiah.

Materi yang disampaikan juga turut memberikan hasil efektif ini. Peneliti, dalam menyampaikan materi soteriologi alkitabiah, mengutamakan materi dari eksposisi kitab Injil Sinoptik, Injil Yohanes dan surat Yohanes. Salah satu contohnya adalah bahan KTBK Teguh dalam Kristus yang merupakan bahan pemuridan berdasarkan eksposisi surat I-III Yohanes. ${ }^{33}$ Bahan ini diberikan sebagai tugas studi mandiri dan bahan kelompok pemahaman Alkitab. Materi ini memberi memberikan informasi tentang karya Yesus secara lengkap dan alkitabiah kepada mahasiswa.

\section{KESIMPULAN}

Kesimpulan yang diambil berdasarkan hasil dan pembahasan penelitian ini yaitu pertama, pengajaran mata kuliah PAK menyumbangkan 13,5\% pemahaman mahasiswa Kristen Universitas Sebelas Maret tentang soteriokogi alkitabiah. Kedua, pengajaran mata kuliah PAK sangat diperngaruhi penyampaian dan pengkomunikasian materi pembelajaran tema soteriologi alkitabiah secara berulang-ulang disertai metode yang bervariasi dan fokus pada materi eksposisi Injil Sinoptik, Injil Yohanes, dan Surat Yohanes.

Peneliti memberikan tiga rekomendasi terkait kesimpulan penelitian ini. Rekomendasi pertama yaitu para dosen mata kuliah PAK di Perguruan Tinggi untuk lebih fokus pada materi soteriologi menurut Injil. Oleh karena itu para dosen mata kuliah PAK harus mengubah Rencana Pembelajaran Semester mata kuliah PAK yang dibuat dan memfokuskan pada materi pembelajaran topik soteriologi berisi eksposisi Alkitab. Rekomendasi kedua para dosen mata kuliah juga harus menyampaikan materi soteriologi alkitabiah menggunakan metode yang bervariasi baik intrakulikuler maupun ekstrakulikuler. Dengan rekomendasi ini, dosen mata kuliah dapat berjumpa dengan mahasiswa Kristen lebih banyak dari standar yaitu 16 kali pertemuan. Rekomendasi terakhir yaitu bagi para peneliti lain. Peneliti berharap ada penelitian lebih lanjut untuk mengukur efektivitas setiap metode pembelajaran dalam pengajaran mata kuliah PAK di Perguruan Tinggi.

\footnotetext{
${ }^{33}$ Timotius Haryono, Teguh Dalam Kristus (Surakarta: Yayasan Gamaliel, 2018), 12-13.
} 


\section{REFERENSI}

Anderson, Neil T. Siapa Anda Sesungguhnya. Bandung: Lembaga Literatur Baptis, 1997.

Anderson, Neil T., and Rich Miller. Freedom From Fear. Batam: Interaksara, 2002.

Carson, D.A, and Donald Guthrie. Tafsiran Alkitab Abad Ke-21. Jakarta: Yayasan Komunikasi Bina Kasih/OMF, 2017.

Direktur Jenderal Pendidikan Tinggi Departemen Pendidikan Nasional Republik Indonesia. Rambu-Rambu Pelaksanaan Mata Kuliah Pengembangan Kepribadian Di Perguruan Tinggi (2020).

Harmadi, Mariani, and Agung Jatmiko. "Pembelajaran Efektif Pendidikan Agama Kristen Generasi Milenial.” PASCA : Jurnal Teologi Dan Pendidikan Agama Kristen 16, no. 1 (2020): 62-74. https://doi.org/10.46494/psc.v16i1.72.

Haryono, Timotius. "Hubungan Pendidikan Agama Kristen Di Universitas Sebelas Maret Dengan Pemahaman Soteriologi Mahasiswa." Jurnal Penelitian Sekolah Tinggi Teologi Gamaliel 1, no. 2 (2013): 83-91.

- Pendidikan Agama Kristen. Surakarta: Lembaga Pengembangan dan Penjaminan Mutu Pendidikan (LPPMP) Universitas Sebelas Maret, 2016.

. "Saved By Faith." Sura: Yayasan Gamaliel, 2018.

—. Teguh Dalam Kristus. Surakarta: Yayasan Gamaliel, 2018.

Heath, Stanley. Penginjilan Dan Pelayanan Pribadi. Surabaya: Yakin, 1979.

Heath, W. Stanley. Tak Mengambang Tak Meleset. Yogyakarta: Yayasan Andi, 1989.

Jura, Demsy. "Kajian Soteriologi Dalam Teologi Universalisme, Calvinisme, Dan Arminianisme

Serta Kaitannya Dengan Pembelajaran Pendidikan Agama Kristen." Shanan Jurnal Pendidikan Agama Kristen, 2017. http://repository.uki.ac.id/id/eprint/282.

Kawangmani, Soleman, and Irawan Budi Lukmono. "Efektivitas Pembelajaran Agama Kristen Melalui Mata Kuliah Pendidikan Agama Kristen Di Perguruan Tinggi Terhadap Pemahaman Mahasiswa Kristen Tentang Gambar Diri." Jurnal Gamaliel : Teologi Praktika 2, no. 1 (2020). https://doi.org/10.38052/gamaliel.v2i1.48.

Mardiharto. "Pembangunan Sumber Daya Manusia Melalui Bidang Pendidikan Agama Kristen." PASCA: Jurnal Teologi Dan Pendidikan Agama Kristen 15, no. 2 (2019): 28-32.

Niftrik, G.C. van, and B.J. Boland. Dogmatika Masa Kini. Jakarta: BPK Gunung Mulia, 2015.

Nuhamara, Daniel. Pendidikan Agama Kristen. Bandung: Bina Media Informasi, 2005.

Nurwardani, Paristiyanti. Pedidikan Agama Kristen. Direktorat Jenderal Pembelajaran dan Kemahasiswaan Kementerian Riset, Teknologi, dan Pendidikan Tinggi Republik Indonesia, 2016.

Nurwindayani, Efi. "Doktrin Keselamatan Untuk Orang Kristen Jawa." Jurnal Penelitian Sekolah Tinggi Teologi Gamaliel 5, no. 2 (2017): 36-42.

Presiden Republik Indonesia. Undang-Undang Republik Indonesia Nomor 12 Tahun 2012 tentang Pendidikan Tinggi (2012).

Sihombing, Hendra M. "Soteriologi Dalam Pendidikan Agama Kristen," 2012. Sugiyono. Metode Penelitian Tindakan Komprehensif. Bandung: Alfabeta, 2015.

Tong, Stephen. Dosa, Keadilan Dan Penghakiman. Jakarta: Lembaga Reformed Injili Indonesia, 1993. 